\title{
ABORDAGEM SOCIETAL DAS REPRESENTAÇÕES SOCIAIS
}

\author{
Angela Maria de Oliveira Almeida*
}

Resumo: O propósito deste artigo é apresentar as principais contribuições de Willem Doise para o desenvolvimento da teoria das representações sociais. Nesta direção, foram examinados: a Teoria das Representações Sociais como a grande teoria; a criação do Laboratório de Psicologia Social Experimental na Universidade de Genebra; os estudos experimentais sobre o desenvolvimento social da inteligência; os estudos experimentais das representações sociais; os quatro níveis de análise em Psicologia Social; as relações grupais; o paradigma das três fases; a pesquisa sobre os direitos humanos. Ainda que se considere que a adesão à Teoria das Representações Sociais pressupõe o estudo de indicadores que organizam o campo representacional, a análise dos posicionamentos individuais neste campo e a ancoragem destes posicionamentos nas dinâmicas societais, é preciso reconhecer que esta forma de fazê-lo ainda é pouco difundida nos meios científicos da América Latina.

Palavras-chave: representações sociais, abordagem societal, Willem Doise.

Há quase 50 anos o estudo das representações sociais (RS), originalmente desenvolvido na Psicologia Social, vem se constituindo num campo de investigação importante nas ciências sociais e humanas. Novas fronteiras são abertas, estabelecendo interfaces com diferentes áreas de conhecimento, como a Sociologia, a Antropologia, a Linguística e as Ciências Políticas. No Brasil, o estudo das RS foi introduzido por brasileiros que tinham frequentado, em Paris, a École de Hautes Études en Sciences Sociales (EHESS)

\footnotetext{
* Professora do Departamento de Psicologia Social e do Trabalho. Coordenadora do Programa de Pós-Graduação em Psicologia Social, do Trabalho e das Organizações. Instituto de Psicologia. Universidade de Brasília. E-mail: aalmeida@unb.br
} 
durante os anos 1970, onde cursaram disciplinas e realizaram suas teses com Serge Moscovici e Denise Jodelet. Naquela época, os latino-americanos encontravam na EHESS um espaço para refletir sobre os problemas que afligiam seus países. O estudo das RS se insinuava como uma resposta aos problemas emergentes da vida cotidiana, diante dos quais os pesquisadores eram chamados a se posicionar.

A adesão a esta perspectiva psicossociológica não ocorreu, entretanto, sem resistências. No Brasil, de forma semelhante ao que se observou na Europa, entre a publicação da obra seminal de Moscovici, La psychanalyse, son image et son public, em 1961, e a expansão da Teoria das Representações Sociais (TRS) nos meios acadêmicos, assistiu-se a um longo período de latência. As razões foram múltiplas. É interessante começar lembrando que a inserção da TRS no Brasil se deu pela via de universidades situadas fora do eixo Rio-São Paulo, portanto, localizadas em centros considerados periféricos do ponto de vista da produção científica nacional à época: Nordeste e Centro-Oeste do País. Sua chegada ao Brasil, no início da década de 80 , coincide com um período de crise da Psicologia Social, cuja resposta, naquele momento, foi buscada, ainda que por um segmento minoritário, na teoria marxista. A Psicologia Social, naquele momento, dividia-se entre duas vertentes: a primeira, afinada com pesquisadores americanos, centrava-se nos processos intrapessoais e interpessoais ou, para retomar aqui Robert Farr (1993), desenvolvia uma Psicologia Social individual; a segunda, caracterizada por uma abordagem politicamente engajada, apoiava-se "na teoria marxista e na busca de objetos relevantes da nossa realidade, de forma a encontrar explicações para nossos próprios problemas" (Sá, Arruda, 2000, p. 17). Adeptos de ambas as vertentes se opuseram à TRS. No âmbito da psicologia de inspiração americana, o estudo das RS era visto como uma nova roupagem para aquilo que já vinha sendo feito: o estudo das atitudes. Apresentandose como um modelo capaz de oferecer respostas às angústias da 
intelectualidade brasileira, o marxismo constituiu-se em outro vetor de resistência à expansão da teoria, considerando os estudos das RS como um desvio ideológico, marcado pelo viés idealista.

Esta resistência, no entanto, não persistiu por muito tempo. O desenvolvimento de pesquisas colocou em evidência ovalor heurístico do aporte teórico da TRS, fazendo com que o conceito evoluísse na direção de uma teoria amplamente investigada. Atualmente, o estudo das RS encontra-se em plena expansão no Brasil e se observa uma clara ampliação das áreas que têm aderido a este referencial, incluindo, em um primeiro momento, Educação, Saúde e Serviço Social, seguidos pela História, Sociologia, Antropologia, Geografia, Comunicação e Meio Ambiente.

Ampliaram-se também, os trabalhos de pesquisa, o que pode ser constatado pelo número crescente de participantes nos eventos da área. Em 1994, duas centenas de congressistas se reuniram na cidade do Rio de Janeiro, durante a $2^{\text {nd }}$ International Conference on Social Representations (ICRS) - evento itinerante, já realizado nove vezes na Europa, América do Norte, América do Sul e Ásia. Em 1998, em Natal, no Estado do Rio Grande do Norte, foi inaugurada a I Jornada Internacional sobre Representações Sociais (JIRS), que reuniu mais de 200 pesquisadores, docentes e estudantes de todas as partes do País, bem como da França, Grã-Bretanha, Portugal, Suíça, Cuba e Venezuela, para apresentar e discutir seus trabalhos de pesquisa desenvolvidos sob a égide da TRS. Esse evento teve repercussões extremamente importantes para o avanço da pesquisa em RS no Brasil. A partir de 2003, o evento assumiu, também, uma identidade nacional, inaugurando a Conferência Brasileira sobre Representações Sociais (CBRS), com a qual as JIRS passaram a coincidir. Após 10 anos, em 2007, Brasília acolheu a V JIRS e a III CBRS, e, nesse evento, compareceram mais de 900 participantes e foram apresentados 800 trabalhos científicos. Entre a I e V JIRS, observou-se uma nítida ampliação no número de participantes, 
das áreas envolvidas e dos trabalhos apresentados. Certamente, tal crescimento se deve ao fato de que os estudos em RS têm mostrado o quanto esta noção e sua correlata base teórica permitem uma compreensão e explicação aprofundada dos fenômenos sociais.

Em 2009, a IV CBRS, realizada na cidade do Rio de Janeiro, teve como tema central "A Escola Brasileira de Representações Sociais", inspirada na observação de Denise Jodelet que estima que, há pouco mais de dez anos, estamos assistindo ao seu nascimento. Como atesta a organização temática da IV Conferência, acreditase que a Escola Brasileira de RS se estrutura, principalmente, em torno de três abordagens teóricas que se desenvolveram a partir da TRS: a abordagem processual, liderada por Denise Jodelet; a abordagem estrutural, liderada por Jean-Claude Abric e também conhecida como a Escola do Midi; a abordagem societal, liderada por Willem Doise, identificada nos meios acadêmicos como Escola de Genebra. Proponho deter-me aqui sobre esta última, com o claro intuito de difundir a abordagem que considero menos conhecida no Brasil, porém não menos importante. Para tanto, tentarei, ainda que brevemente, traçar a trajetória intelectual de Doise, centrando-me os seguintes pontos:

1) a TRS como a grande teoria;

2) a criação do Laboratório de Psicologia Social Experimental na Universidade de Genebra por Willem Doise;

3) os estudos experimentais sobre o desenvolvimento social da inteligência;

4) os estudos experimentais das RS;

5) os quatro níveis de análise em Psicologia Social;

6) as relações grupais;

7) o paradigma das três fases;

8) a pesquisa sobre os direitos humanos. 


\section{A Teoria das Representações Sociais como uma grande teoria}

Podemos considerar, com Doise (1993, p. 161), que Moscovici tem nos oferecido uma "teoria das representações sociais a qual não é somente heuristicamente útil para analisar complexos fenômenos sociais, mas também capaz de reorganizar teoricamente tradicionais campos de estudo na Psicologia Social". Em Moscovici encontramos conceitos importantes, que funcionam como princípios gerais que oferecem uma estrutura de análise capaz de detalhar o processo de construção ou gênese de uma representação social, mas que não têm a pretensão de esgotar todas as possibilidades teóricas que este campo de estudo suscita. Neste sentido, ela pode ser considerada, como Doise vem assinalando em várias oportunidades, uma grande teoria das representações sociais:

Com efeito, a teoria das representações sociais pode ser considerada como uma grande teoria, grande no sentido de que sua finalidade é a de propor conceitos de base /.../ que devem atrair a atenção dos pesquisadores sobre um conjunto de dinâmicas particulares e suscitar, assim, estudos mais detalhados sobre os múltiplos processos específicos (Doise, 1990, p. 172).

No meu entender, grandes teorias nas ciências humanas são concepções gerais sobre o indivíduo e/ou o funcionamento societal, que orientam o esforço de pesquisa. Elas devem, não obstante, ser completadas por descrições mais detalhadas dos processos que sejam compatíveis com a teoria geral, mas que podem também ser compatíveis com outras teorias (Doise, 1993, p. 161).

Nesta mesma direção, em recente publicação de conferências ministradas durante a V JIRS, Palmonari (2009, p. 45) afirma:

A TRS é agora uma construção muito complexa, uma espécie de encruzilhada: as correntes de idéias que aí convergem são múltiplas e, no momento, não há nenhum mapa que dê as coordenadas comuns. E não é apenas uma questão de idéias e modelos formulados por disciplinas não psicológicas (história, antropologia, sociologia, 
semiótica etc.), mas também produções de grupos diferentes que, de todo modo, compartilham a mesma orientação teórica em psicologia social.

A grande teoria conheceu vários desdobramentos. Como assinalado acima, no Brasil, observa-se uma maior inserção de três grandes pesquisadores, com suas respectivas abordagens Abric, Doise e Jodelet -, todos eles discípulos de Moscovici", mas que representam diferentes formas de enfocar e investigar as representações, tendo cada um deles trazido uma contribuição particular para o desenvolvimento da TRS. Sá (1998, p. 65) chama a atenção para o caráter complementar que essas abordagens assumem: "A grande teoria das representações sociais [...] desdobra-se em três correntes teóricas complementares [...]. Não se trata por certo de teorias incompatíveis entre si, na medida em que provêm todas de uma mesma matriz básica e de modo algum a desautorizam”.

\section{A criação do Laboratório de Psicologia Social Experimental em Genebra}

Após e em consequência do movimento estudantil de 1968, que reivindica a inserção da disciplina Psicologia Social no curso de Psicologia, Jean Piaget convidou Serge Moscovici para assumir essa disciplina. Na impossibilidade de assumir essa responsabilidade de forma definitiva, Moscovici, juntamente com Claude Flament e Claudine Herzlich, conduziu, durante certo tempo, um seminário aprofundado em Psicologia Social, enquanto Willem Doise, na época um jovem doutor, assumia a disciplina Introdução à Psicologia Social, entre 1970 e 1972 . Em outubro de 1972, Doise tornou-se professor de Psicologia Social Experimental na Universidade de Genebra, após ter se apresentado a um concurso. Foi necessário pouco tempo para que se formasse, com Doise, um grupo de pesquisa em Psicologia Social Experimental: Gabriel Mugny, Claude Deschamps, Anne Sinclair, Anne-Nelly Perret-Clermont e Marisa Zavalloni. Com os 
anos, a esse grupo se agregaram outros pesquisadores, como Alain Clémence, Fabio Lorenzi Cioldi, Dario Spini, Monique Herrera, Christian Staerklé, Fabrice Buschini...

Ao se centrar na intervenção dos sistemas de crenças compartilhadas sobre a organização e o funcionamento cognitivos, Doise tornou-se o "advogado de uma abordagem societal da Psicologia Social” (Staerklé, Spini, 2004, p. 16, grifos nossos). O grupo, liderado por Doise na Suíça, articula as RS com uma perspectiva mais sociológica, enfatizando a inserção social dos indivíduos como fonte de variação dessas representações. Nesta direção, é evidente o objetivo dessa abordagem em conectar o individual ao coletivo, de buscar a articulação de explicações de ordem individual com explicações de ordem societal, evidenciando que os processos de que os indivíduos dispõem para funcionar em sociedade são orientados por dinâmicas sociais (interacionais, posicionais ou de valores e de crenças gerais).

\section{Os estudos experimentais sobre o desenvolvimento social da inteligência}

Inspirado nas ideias de Piaget, que atribuiu um papel importante aos determinantes sociais do desenvolvimento cognitivo e, em algumas ideias de Vygotsky, os psicólogos sociais de Genebra tiveram como objetivo inicial mostrar, com métodos experimentais, que as interações sociais podem favorecer o aparecimento e o desenvolvimento de certas operações cognitivas. Foi o caso, por exemplo, do desenvolvimento social da inteligência na criança. Era preciso mostrar que elementos do ambiente social, como as normas, as representações e as regras, organizam as relações sociais das quais a criança faz parte e agem como reguladores de suas atividades. Tratava-se de mostrar experimentalmente que há uma apropriação individual dos instrumentos cognitivos socialmente construídos e 
que as crianças se saem melhor nas tarefas cognitivas quando as realizam em situações grupais ou com um adulto (Doise, Mugny, 1981). Este foi o caso, por exemplo, do desenho experimental com três fases, utilizado por Doise e seus colaboradores para evidenciar o efeito da interação social sobre o desenvolvimento da inteligência. $\mathrm{Na}$ primeira fase, a criança realizava individualmente uma tarefa; na segunda, a tarefa era realizada por um conjunto de crianças em que algumas já tinham adquirido a noção de conservação ${ }^{2}$ e outras que não tinham adquirido essa noção. Na terceira, as crianças eram avaliadas individualmente e se demonstrava que a situação de interação favorecia a aquisição da noção de conservação. No entanto, Doise e Mugny (1991, p. 11) assinalaram que o progresso cognitivo não se dá de forma automática: "a interação social não tem poderes mágicos".

$\mathrm{Na}$ esteira da Psicologia Social Experimental que vinha estudando o conflito como fator desencadeante de mudanças estudo da dissonância cognitiva em Festinger (1957), efeito das divergências de opinião sobre a polarização coletiva (Doise, Moscovici, 1984), da influência minoritária (Moscovici, 1979) e seguindo as ideias de Piaget (1965) acerca da origem social da descentração, ${ }^{3}$ o grupo de Genebra vai sustentar que os conflitos sociocognitivos suscitados pela interação social é que a tornam uma fonte de progresso cognitivo. Ou seja,

há um conflito sociocognitivo quando, em uma mesma situação [de interação social], são produzidos socialmente diferentes enfoques cognitivos para o mesmo problema. Em condições adequadas, a presença desses diferentes pontos de vista pode favorecer sua coordenação dentro de uma nova solução mais complexa, porém mais conveniente que qualquer dos enfoques prévios considerados isoladamente (Doise, 1991, p.15).

Os estudos experimentais acerca do conflito sociocognitivo conduziram Mugny e Doise (1983) a elaborar o conceito de "marcação social": uma tarefa cognitiva é marcada socialmente 
quando as respostas cognitivas implicadas em sua resolução estão impregnadas dos significados sociais que esta tarefa pode ter. De acordo com Doise (1991a, p. 17) três aspectos definem a concepção atual de marcação social:

1. A marcação social define qualquer situação onde se dá uma correspondência entre as respostas que derivam das regulações sociais e as respostas que resultam da organização dos esquemas cognitivos /.../; 2. para dar lugar a um desenvolvimento cognitivo, esta correspondência deve levar o sujeito a comparar efetivamente respostas de diferentes naturezas; 3. o mecanismo pelo qual a marcação social garante a elaboração de novas respostas cognitivas é o conflito sócio-cognitivo, ou seja, é a confrontação de respostas contraditórias que pode dar lugar a novas respostas.

Ao se admitir esta ideia, pode-se considerar o desenvolvimento sociocognitivo como resultante, ao mesmo tempo, da apropriação da herança cultural e do questionamento de respostas que fazem parte dessa mesma herança. Com este conceito fica evidente como os estudos sobre as interações sociais deixaram suas marcas sobre os estudos experimentais do "desenvolvimento social da inteligência".

\section{Os estudos experimentais das representações sociais}

Passamos agora ao legado teórico-metodológico construído por Doise e seus colaboradores para o estudo das RS. A trajetória experimental de Doise seguiu um caminho que revelava, desde seu início, uma ruptura com os métodos experimentais tradicionais. Como ele próprio afirmou, “o procedimento experimental, apoiado pelo paradigma experimental tradicional - que cristaliza os fenômenos quando são isolados das dinâmicas sociais mais complexas - tem tendência a ativar uma representação empobrecida da realidade social" (Doise, 1982, p. 27). A experimentação tradicional centrase sobre os paradigmas e se esquece de seu contexto social. Uma vez mais, opera-se a oposição entre o psicológico - estudado 
experimentalmente - e o sociológico - aparentemente não passível à experimentação. Deve-se concluir que Wundt tinha razão? Seria o caso se a experimentação devesse, necessariamente, limitar-se ao estudo de processos intra e interindividuais, sem que pudesse, ao mesmo tempo, examinar a articulação desses processos com as dinâmicas de natureza mais sociológica. Centrado sobretudo nos estudos das interações sociais, Doise (1982) preconiza um procedimento experimental que leve em conta as normas e as representações construídas nas relações sociais vividas, e com as quais os sujeitos respondem na situação experimental.

Doise, Deschamps e Mugny ([1978] 1991, p. 6) já afirmavam, quando da publicação do livro Psychologie sociale expérimentale, que:

Longe de despir os sujeitos experimentais de qualquer determinação exterior à situação experimental, o procedimento que preconizamos, ao contrário, trabalha sobre as normas de comportamentos e de representações que os sujeitos trazem com eles para a situação experimental. Nisto, nosso procedimento difere notavelmente daqueles que visam construir situações de interações ditas mínimas, que não levam em consideração as relações sociais anteriormente vividas.

Os trabalhos experimentais realizados por Doise seguiram um encadeamento muito nítido. De uma constatação inicial da necessidade de ultrapassar os postulados teóricos, particularmente os postulados frequentemente utilizados pela Psicologia Social, ele passa pela experimentação em Psicologia do Desenvolvimento Sociocognitivo, dirigindo-se aos estudos das representações das relações sociais entre grupos.

No que concerne particularmente à experimentação aplicada aos estudos das RS, as investigações de Doise estiveram, desde seu início, centradas nas relações entre grupos e, em Genebra, ele retoma um caminho já iniciado em Paris com Moscovici, quando 
trabalharam sobre a polarização coletiva (Doise, 1969, 1972, Doise; Moscovici, [1969] 1970).

Resultados de pesquisas efetuadas nos Estados Unidos foram interpretados por Doise (1972) como uma representação que teve uma função justificadora de uma situação de segregação. Os resultados dessas pesquisas mostravam que os policiais brancos superestimam a criminalidade negra (Kephart, 1954), assim como os alunos brancos subestimavam o desempenho escolar dos colegas negros (Clarke; Campbell, 1955). Os resultados de uma experiência realizada por Doise (1971) também mostraram a função de antecipação das representações. Após um intervalo de familiarização com a situação experimental, era pedido aos sujeitos que pertenciam a grupos diferentes, para descreverem o outro grupo, o seu parceiro e a eles mesmos, usando uma escala de motivação. Os resultados mostraram que antes que a interação ocorresse,

[...] os sujeitos já atribuíam motivações menos cooperativas ao grupo adverso que ao seu parceiro ou a eles mesmos. Bastava uma representação da interação futura para provocar uma imagem do outro grupo que não tinha qualquer impacto, além de influenciar o comportamento a seu respeito. (Doise, 1971, p. 210).

Observa-se, assim, um esforço da equipe liderada por Doise para caminhar no sentido contrário àquele advertido por ele ao nos lembrar dos perigos do método experimental, quando se esquece que os processos estudados estão todos inseridos "em um contexto social que ultrapassa largamente a situação experimental" (Doise, 1982, p. 26).

Com a TRS esboça-se uma evolução na direção de uma psicossociologia experimental, o que implica uma obrigatória e progressiva inserção do social na experimentação. Nas palavras de Doise (1982, p. 26), para “[...] estudar a articulação entre o psicológico e o sociológico, é preciso introduzir nos modelos explicativos as variáveis pré-existentes na situação experimental [...]”. 


\section{A integração de quatro níveis de análise: processos intraindividuais, interpessoais, intergrupais e societais}

A abordagem societal pressupõe a integração de quatro níveis de análise no estudo das RS. O primeiro focaliza os processos intraindividuais, analisando o modo como os indivíduos organizam suas experiências com o meio ambiente. O segundo centra-se nos processos interindividuais e situacionais, buscando nos sistemas de interação os princípios explicativos típicos das dinâmicas sociais. $\mathrm{O}$ terceiro refere-se aos processos intergrupais, leva em conta as diferentes posições que os indivíduos ocupam nas relações sociais e analisa como essas posições modulam os processos do primeiro e do segundo níveis. O quarto, o societal, enfoca os sistemas de crenças, representações, avaliações e normas sociais, adotando o pressuposto de que as produções culturais e ideológicas, características de uma sociedade ou de certos grupos, dão significação aos comportamentos dos indivíduos e criam as diferenciações sociais, a partir de princípios gerais. Apesar de análises que articulam os vários níveis teóricos serem mais completas e conduzirem a uma melhor descrição do processo conceitualizado em cada um dos quatro níveis, as análises que recorrem às explicações do tipo societal (isto é, posicional e ideológica) ainda permanecem minoritárias em Psicologia Social.

Doise (1993) considera que os estudos iniciados por Serge Moscovici ([1961] /1976), fornecem, atualmente, o quadro mais estimulante para se construir uma Psicologia Societal, fazendo imbricar o estudo dos sistemas cognitivos, acessados no nível individual, no estudo dos sistemas relacionais e societais. A proposta de análise das RS a partir desses quatro níveis pauta-se na noção de RS como princípios geradores de tomadas de posição, ligados às inserções sociais específicas, organizando os processos simbólicos que interferem nas relações sociais. Tal entendimento levou Doise e colaboradores a definir o estudo das RS como "a análise das regulações efetuadas pelo metasistema das relações 
sociais simbólicas nos sistemas cognitivos individuais", o qual deve responder à seguinte questão: "quais regulações sociais atualizam quais funcionamentos cognitivos em quais contextos específicos?" (Clémence; Doise; Lorenzi-Cioldi, 1994, p. 120).

\section{As relações grupais}

A articulação dos quatro diferentes níveis de análise (individual, interpessoal, grupal e societal) foi particularmente investigada por Doise e colaboradores, na década de 70, nos estudos das relações intergrupais. De fato, é preciso deixar aqui registrado que o estudo das RS em Genebra articula-se, desde o seu início, com o estudo das relações entre grupos. Doise (1972), apoiado no pressuposto de que "a representação entre grupos se forma através dos julgamentos dos grupos sobre os outros" (p. 206), vai mostrar, a partir dos estudos do estereótipo, da categorização e da polarização coletiva, "a necessidade e o interesse de se estudar as dinâmicas representacionais exatamente onde elas se produzem, ou seja, no contexto das relações sociais, sendo estas justificadas e antecipadas por aquelas" (p. 206, grifos do autor).

O conteúdo das representações depende das relações entre os grupos, na medida em que serve para justificar certo modo de encadeamento das relações, mantendo, ao mesmo tempo, a especificidade e a identidade de cada grupo. "Isso não significa que a representação apenas segue - adaptando-se e justificando - o encadeamento da interação, mas ao contrário, ela intervém, antecipando-o ativamente, na determinação deste encadeamento" (Doise, 1972, p. 210).

Um estudo importante nesta direção foi aquele realizado por Doise, em 1972, e que será publicado quase 10 anos depois, no livro de Explicação em Psicologia Social. Trata-se de um estudo de comparação entre grupos (o meu grupo e o outro grupo), 
realizado com jovens de nível médio (orientação acadêmica e profissional). Nesse estudo, Doise e Mugny (1991, p. 18) descrevem o funcionamento individual em grupo e o processo de categorização social, e, ao mesmo tempo, postulam que as condições que "possibilitam este funcionamento dependem também de análises no nível interindividual (situações de encontro) e posicional (assimetrias de status entre as duas categorias)". Ao investigar o impacto das múltiplas pertenças sociais (categorização simples: homens versus mulheres; categorização cruzada: diferenciação por sexo e tipo de grupo - grupo azul versus grupo vermelho), pode-se constatar que em condição de categorização simples (pertença por sexo) os sujeitos fazem avaliações distintas in-group e out-group. Todavia, esta diferença desaparece quando os sujeitos são inseridos na condição de categorização cruzada (sexo e cor). Os estudos sobre os processos de categorização social para além do nível intraindividual (Doise; Sinclair, 1973, Doise, 1972, 1973, Deschamps; Doise, 1978) evidenciaram a fluidez da noção de estereótipos vis-à-avis as dinâmicas de categorização e de comparação social, ou seja, os estereótipos intervêm com maior força quando membros de uma categoria social se encontram com membros de outra categoria, ao contrário do que ocorre em encontros individuais de duas pessoas pertencentes a categorias distintas, já que nesta situação intervêm múltiplas pertenças.

Ainda no âmbito dos estudos sobre as relações intergrupais, Doise traz uma importante contribuição para a compreensão do funcionamento das identidades coletivas e individuais. No processo de categorização social - além da tendência de grupos distintos acentuarem suas diferenças e semelhanças, além da tendência dos grupos de status superior marcarem mais claramente a distância em relação aos grupos de status inferior ao se avaliarem reciprocamente-, no nível do comportamento, as relações estabelecidas se modificam, com os grupos de menor status ou menos consolidados evidenciando uma maior discriminação ao se referirem ao outro grupo. Tudo se 
passa como se estes grupos, "ao reconhecerem seu status menos favorável, tendem ativamente a inverter as relações dominantes" (Doise; Mugny, 1991, p. 19). Esses estudos, iniciados por Doise, tiveram sua continuação, por exemplo, nas pesquisas de Deschamps (1991), que redundam no modelo da covariação entre semelhanças e diferenças, e de Lorenzi-Cioldi (1988), ao mostrar que, nas relações entre grupos dominantes e dominados, os primeiros atribuem aos segundos uma identidade coletiva, enquanto reservam para si e para os membros de seu grupo uma identidade individual.

\section{O paradigma das três fases}

Coerente com esses pressupostos, Doise, Clémence e Lorenzi-Cioldi (1992) e Clémence, Doise e Lorenzi-Cioldi (1994) propuseram uma abordagem tridimensional para estudar as RS. Palmonari (2009) considera esta abordagem - por ele denominada, "o paradigma das três fases - como uma das contribuições importantes de Doise e colaboradores, sobretudo entre aqueles que visam uma elaboração teórica das RS. Para elaborar este modelo metodológico, Doise se inspirou fundamentalmente na obra seminal de Moscovici ([1961] 1976), particularmente nas dinâmicas de comunicação (difusão, propagação e propaganda), no interior das quais as RS são fabricadas. De acordo com Palmonari, o paradigma das três fases pode ser interpretado como uma resposta crítica de Doise aos estudos que se concentraram na identificação dos elementos consensuais das RS.

Doise exprime a exigência de uma concepção "mais completa" das RS. Nesta concepção necessita-se reconhecer sempre a existência de um campo simbólico comum (compartilhado) em relação ao qual os indivíduos ou os subgrupos tomam posições variadas. Isto porque se tem como objetivo explicar as variações entre indivíduos decorrentes de suas inserções específicas em um conjunto de relações sociais simbólicas em um dado momento. (Palmonari, 2009, p. 45). 
O modelo tridimensional ou das "três fases" pressupõe uma hipótese específica para cada fase (Doise, 2002). A primeira hipótese é que há uma partilha de crenças comuns, entre os diferentes membros de uma população, acerca de um dado objeto social, visto que as RS se constroem em relações de comunicação que supõem linguagem e referências comuns àqueles que estão implicados nessas trocas simbólicas. Estudar as RS nesta fase significa identificar os elementos dessa base comum e a forma como eles se organizam, ou seja, tratar-se do campo comum das representações sociais.

A segunda hipótese refere-se à natureza das diferenças, das heterogeneidades nas tomadas de posições em relação a um dado objeto de representação. Trata-se de explicar como e porquê os indivíduos se diferenciam entre si nas relações que eles mantêm com esses objetos de representação. Nesta fase, estudar as representações equivale a identificar os princípios organizadores das variações individuais.

A terceira hipótese considera que as RS, além de exprimirem um consenso entre indivíduos, marcado por certas modulações ou oposições individuais, são também caracterizadas por ancoragens das tomadas de posição em outras realidades simbólicas coletivas. Elas se explicitam nas hierarquias de valores, nas percepções que os indivíduos constroem das relações entre grupos e categorias e nas experiências sociais que eles partilham com o outro, em função de sua pertença e posição. Nesta fase, a ênfase do estudo das RS recai sobre a ancoragem das diferenças individuais.

Como afirma Doise (2001, p. 146), "entendimento comum, organização das tomadas de posição individuais, figuras de ancoragem [...], são estas as três fases que ritmam nossas pesquisas sobre representações sociais...”.

Segundo Palmonari (2009, p. 46), 
o modelo das três fases, em resumo, tenta traduzir, em um discurso articulado, aquilo que Moscovici disse na segunda parte do seu livro: para apreender uma RS é necessário articular os estudos das dinâmicas das relações e da comunicação com o estudo dos processos psicológicos que as acompanham. Para apreender a especificidade do aspecto social das representações é necessário estudar a sua função na dinâmica das comunicações e das relações sociais.

A proposta de análise tridimensional das RS, formulada por Doise, Clemence e Lorenzi-Cioldi (1992) encontra suporte nos métodos de análises de dados quantitativos aplicados ao estudo das RS, nos quais os questionários ocupam uma posição privilegiada. Tais análises permitem identificar os eixos ou os fatores gerais que organizam uma representação social.

\section{As representações sociais dos direitos humanos: uma análise tridimensional}

As elaborações teórico-metodológicas de Doise e colaboradores o conduziram a um programa de pesquisa sobre os direitos humanos, focando, particularmente, a aplicação dos princípios presentes na Declaração Universal dos Direitos Humanos (DUDH) e os limites da sua aplicação a certos indivíduos ou grupos sociais.

Com esse programa de pesquisa, Doise (2001) ampliou os estudos sobre os direitos humanos para além da Filosofia, do Direito e das Ciências Políticas, trazendo um olhar psicossociológico sobre o fenômeno. A partir de uma estrutura conceitual compreensiva, os direitos humanos passaram a ser estudados como representações sociais normativas que se organizam no âmbito da esfera pública, adotando-se a abordagem tridimensional.

Esse programa de pesquisa se estendeu, por mais de 20 anos, a 35 países pertencentes aos cinco continentes. Foram analisados mais de seis mil questionários, compostos por duas partes. Na primeira parte 
eram apresentados os 30 artigos da DUDH, de 1948, que deveriam ser avaliados pelos sujeitos em oito escalas, as quais contemplavam três dimensões: 1) importância do artigo: compreensão, acordo, implicação para a vida privada, responsabilidade com o outro; 2) implicação pessoal: "eu faço qualquer coisa", "ajudo aos que estão se esforçando"; 3) eficácia do governo e dos partidos políticos: "os partidos políticos podem ajudar muito", "medidas fáceis de serem aplicadas pelos governantes". A segunda parte do questionário era composta de três outras sessões:

1) Valores - itens relativos à paz, igualdade, estética, liberdade, segurança, felicidade, harmonia, amor, prazer, saúde, reconhecimento social, sabedoria, amizade, autorespeito...;

2) Percepção de conflitos entre os indivíduos em função da idade, sexo, raça, cor, língua, religião, origem geográfica, opinião política ou de outra natureza, origem nacional ou social, riqueza, nascimento;

3) Experiências de injustiça em função da pertença a alguma das categorias acima descritas.

Sem desconhecer os perigos de uma simplificação, pontuamos aqui rapidamente os passos seguidos nas análises de cada uma das três fases. ${ }^{4}$

Para se examinar o campo comum das representações, primeira fase, considerou-se apenas a primeira parte do questionário: os 30 artigos da DUDH, avaliados a partir das oito escalas. Neste caso, foi feita uma classificação dos 30 artigos a partir da aproximação das médias de cada sujeito no conjunto das oito escalas.

Na fase 2, variação das tomadas de posição individuais, foram realizadas dois tipos de análises. Na primeira, foram feitas análises do tipo "pancultural", sobre o total de sujeitos das 35 amostras, 
portanto, sem levar em conta a nacionalidade. Na segunda, foram feitas análises do tipo individual, nas quais utilizava-se um score individual (média individual para cada uma das oito escalas, para o conjunto dos 30 artigos), subtraindo-se a média individual da média nacional, para cada variável. Com esses scores, foi possível classificar, em um número limitado, o conjunto dos indivíduos, em função das semelhanças das respostas.

Finalmente, na fase 3, ancoragem das variações individuais, foram realizadas análises fatoriais de componentes principais, tanto sobre os dados "panculturais" como sobre os dados individuais obtidos nas escalas de valores, percepção de conflito e experiências de injustiça.

Os resultados obtidos por Doise (2001) evidenciam que os direitos humanos se apóiam em um entendimento comum, constituindo uma espécie de "cultura universal", correspondendo ao que Jesuíno (2004, p.122) denomina como a "faceta "suprapositiva" a dimensão normativa invocada para (re)presentar os direitos humanos". Para este autor, os resultados empíricos obtidos com este programa de pesquisa estariam próximos do otimismo moderado de Habermas, ao sustentar que os direitos humanos se associam mais à idéia de liberdade individual do que a preceitos jurídicos, de origem moral. Tal afirmação apóia-se no fato de que foi identificado um alto grau de compartilhamento dos 30 artigos da DUDH entre os participantes dos 35 países investigados. Todavia, esse compartilhamento não se mostrou incompatível com a presença de variações individuais, tendo sido identificados vários perfis típicos. Os achados de Doise mostraram que, apesar de haver uma alta concordância com os conteúdos dos artigos da DUDH, há diferenças de grau nessa concordância, observadas nas diferenciações da responsabilidade atribuída aos diferentes atores sociais para a garantia dos direitos humanos. 


\section{Concluindo}

O propósito deste artigo foi de evidenciar os aspectos sobre os quais se concentram as principais contribuições de Willem Doise: seus estudos experimentais, o desenvolvimento social da inteligência, os níveis de análise, as relações grupais, o paradigma das três fases, os direitos humanos. Todas essas contribuições estão alinhavadas pelas representações sociais.

Espera-se ter conseguido mostrar, neste rápido sobrevôo, o comprometimento de Doise com uma Psicologia Social focada nas relações sociais, o que o faz reconhecidamente, como afirma Jodelet (2004, p. 146), "o homem dos laços sociais". Ao se instalar em Genebra, em 1972, Doise levou em sua bagagem, "a idéia que a Psicologia Social deveria, antes de tudo, buscar 'conectar o individual e o coletivo'. Sua motivação fundamental de estudar as relações entre os grupos e os indivíduos, de enfatizar e empiricamente colocar em relevo a influência de fatores sociais sobre o funcionamento cognitivo individual está na base do que mais tarde será conhecido como a escola de Genebra de Psicologia Social" (Staerklé; Spini, 2004, p. 16, grifo dos autores), ou, como ele próprio prefere - a abordagem societal das RS.

Não se pode negar que, com a abordagem societal pautada numa abordagem psicossocial, Doise impõe definitivamente um redimensionamento do que se entende por experimentação em Psicologia Social. Alguns anos após Doise, Deschamps e Mugny terem publicado, em 1978, o livro Psychologie Sociale Expérimentale, Abric (1989, p. 187) vai afirmar que "numerosas críticas são dirigidas à abordagem experimental na Psicologia Social: artificialidade das situações, foco sobre o estudo de fatores isolados de seu contexto, não consideração dos determinantes exteriores ao laboratório: sociológicos, ideológicos, etc". Entretanto, ele estima que com a abordagem experimental na TRS se pode ultrapassar as críticas do "vazio experimental", já que tal abordagem supõe que a 
introdução das RS na situação experimental assegura que o sujeito reaja a uma realidade representada, isto é, a uma realidade apropriada e ressignificada pelos a priori, pelos sistemas de pensamento préexistentes e pelos sistemas interpretativos.

Ainda que se considere que a adesão à TRS pressupõe o estudo de indicadores que organizam o campo representacional, com a análise dos posicionamentos individuais neste campo e a ancoragem desses posicionamentos nas dinâmicas societais, é preciso reconhecer que esta forma de fazê-lo ainda precisa ser mais difundida nos meios científicos da América Latina. Um caminho ainda a ser aberto.

\section{Notas}

1 Abric, Doise e Jodelet, nesta exata ordem de chegada, trabalharam juntos como assistentes de pesquisa, na década de 1960, no então recém- criado Laboratório de Psicologia Social, cujo diretor era Serge Moscovici. Em 1968, Abric assumiu uma cadeira na Universidade de Provence, onde criou, logo em seguida, juntamente com Claude Flament, o Laboratório de Psicologia Social. Doise, em 1970, começou a ministrar algumas aulas de Psicologia Social na Universidade de Genebra e, em 1972, passou a ocupar o posto de professor de Psicologia Social Experimental. Jodelet a última a chegar, lá permaneceu até sua aposentadoria, tendo substituído Moscovici na Direção do Laboratório, quando ele se aposentou. Ainda hoje, Moscovici e Jodelet mantêm um importante trabalho de aprofundamento e difusão da teoria.

2 A noção piagetiana de conservação se refere à capacidade de a criança perceber que um objeto permanece constante mesmo quando se modifica sua aparência. Por exemplo, um mesmo volume de massinha de modelar apresentada na forma de bola e de rolinho.

3 Descentração refere-se à capacidade do indivíduo em coordenar o seu ponto de vista com o do outro. 
4 Para uma leitura detalhada de cada um dos passos seguidos e das análises estatísticas utilizadas, cf. Doise (2001).

\title{
The societal approach of social representations
}

\begin{abstract}
The aim of this paper is to present the main contributions of Willem Doise to the development of the Social Representations Theory. The following topics were examined: the Social Representations Theory as the grand theory; the foundation of Experimental Social Psychology Laboratory in University of Geneva; the experimental studies in social development of intelligence; the experimental studies in Social Representations; the four levels of analysis in Social Psychology; group relationships; the paradigm of three level and the human rights research. The adherence to the Social Representation Theory assumes the study of indicators that organize the representational field, the analysis of the individual positioning in this field and the anchoring of these positioning in the societal dynamics. Nevertheless, it is necessary to admit that this way of analysing is still little diffused in the scientific area of Latin America.
\end{abstract}

Keywords: social representations; societal approach; Willem Doise.

\section{Referências bibliográficas}

ABRIC, Jean-Claude. L'étude expérimentale des représentations sociales. In: JODELET, D. (Ed.). Les représentations sociales. Paris: PUF, 1989. p. 187-203.

CLARKE, Robert B.; CAMPBELL, Donald T. A demonstration of bias in estimates of Negro ability. Journal of Abnormal and Social Psychology, n. 51, p. 585-588, 1955.

CLEMENCE, Alain; DOISE, Willem; LORENZI-CIOLDI, Fabio. Prises de position et principes organisateurs des représentations sociales. In: GUIMELLI, Ch. (Org.), Texte de base en sciences sociales. Structures et transformations des représentations sociales. Paris: Delachaux et Niestlé, 1994. p. 73-84 
DESCHAMPS, Jean-Claude. Identidad, integración y singularización: el modelo de la covariación entre semejanzas y deferencias. Anthropos, n. 124, p. 41-44, 1991.

DESCHAMPS, Jean-Claude; DOISE, Willem. Crossed category memberships in intergroup relations. In: TAJFEL, H. (Ed.). Differences between social groups. London: University Academic Press, 1978.

DOISE, Willem. Relations et représentations intergroupes. In: MOSCOVICI, S. (Ed.). Introduction à la psychologie sociale. Paris: Larousse, 1973. v. 2. p. 194-213.

. Intergroup relations and polarization of individual and collective judgments. Journal of Personality and Social Psychology, n. 12, p. 136-143, 1969.

- An apparent exception to the extremization of collective judgments. European Journal of Social Psychology, n. 1, p. 511$518,1971$.

. Rencontres et représentations intergroupes. Archives de Psychologie, n. 41, p. 303-320, 1972.

. L'Explication en Psychologie Sociale. Paris: P.U.F., 1982

. Les représentations sociales. In: GHIGLIONE, R.; BONET, C.; RICHARD, J. F. (Eds.). Traité de psychologie cognitive, Paris: Dunod, 1990. p. 111-174.

. La doble dinámica social en el desarrollo cognitivo. Anthropos

- Suplementos, n. 24, p. 12-19, 1991a.

. Psicología social del desarrollo. Anthropos - Suplementos, n. 24, p. 6-12, 1991b.

.. Debating social representation. In: BREAKWELL, G. M.; CANTER, D. V. Empirical approaches to social representations. Oxford: Oxford University Press, 1993. p. 157-170. 
DOISE, Willem. Droits de l'homme et forces des idées. Paris: PUF, 2001. . Da Psicologia Social à Psicologia Societal. Psicologia: Teoria e Pesquisa, v. 18, n. 1, p. 27-35, 2002.

DOISE, Willem; MOSCOVICI, Serge. Les decisions de groupe. In: MOSCOVICI, S. (Ed.). Psychologie Sociale. Paris: PUF, 1984.

DOISE, Willem; MUGNY, Gabriel. Le développement social de l'intelligence. Paris: Interéditions, 1981.

DOISE, Willem; MUGNY, Gabriel. Percepción intelectual de un proceso histórico. Anthropos, n. 124, p. 8-24, 1991.

DOISE, Willem; CLEMENCE, Alain; LORENZI-CIOLDI, Fabio. Représentations sociales et analyses des données, Grenoble: PUG, 1992.

DOISE, Willem; DESCHAMPS, Jean-Claude; MUGNY, Gabriel. Psychologie Sociale Expérimentale. Paris: Armand Colin, [1978] 1991.

DOISE, Willem; MOSCOVICI, Serge. Approche et évitement du déviant dans des groupes de cohésion différente. Bulletin de Psychologie, $\mathrm{n}$. 23, p. 522-525, [1969] 1970.

DOISE, Willem; SINCLAIR, Anne. The categorization process in intergroup relations. European Journal of Social Psychology, v. 3, n. 2, p. $145-157,1973$.

FARR, Robert. Theory and method in the study of social representations. In: BREAKWELL, G. M.; CANTER, D. V. Empirical approaches to social representations. Oxford: Oxford University Press, 1993. p. 15-38.

FESTINGER, Leon. A theory of cognitive dissonance. Stanford: Stanford University Press, 1957.

JESUÍNO, Jorge Correia. Humans rights under representation. Nouvelle Revue de Psychologie Sociale, v. 3, n. 1/2, p. 121-124, 2004. 
JODELET, Denise. Écletisme et représentations sociales. Nouvelle Revue de Psychologie Sociale, v. 3, n. 1/2, p. 145-150, 2004.

KEPHART, William M.. Negro visibility. American social Revie, n. 19, p. 462-467, 1954.

LORENZI-CIOLDI, Fabio. Individus dominants et groupes domines: images masculines et feminines. Grenoble: PUG, 1988.

MOSCOVICI, Serge. La psychanalyse, son image et son public, Paris: PUF, [1961] 1976. . Psychologie des minorités actives. Paris: PUF, 1979.

MUGNY, Gabriel; DOISE, Willem. Le marquage social dans le développement cognitif. Cahiers de Psychologie Cognitive, n. 3, p. 89-106, 1983.

PALMONARI, Augusto. A importância da Teoria das Representações Sociais para a Psicologia Social. In: ALMEIDA, A. M. O.; D. JODELET (Orgs.). Representações sociais: interdisciplinaridade e diversidade de paradigmas. Brasília: Thesaurus, 2009.

PIAGET, Jean. Études sociológiques. Genève: Droz, 1965.

SÁ, Celso Pereira. A construção do objeto de pesquisa em representações sociais. Rio de Janeiro: EdUERJ, 1998.

SÁ, Celso Pereira; ARRUDA, Angela. O estudo das representações sociais no Brasil. Revista de Ciências Humanas, Série Especial Temática, Florianópolis, p. 11-32, 2000.

STAERKLÉ, Christian; SPINI, Dario. L'héritage écletique de Willem Doise: une introduction à la Festschrift. Nouvelle Revue de Psychologie Sociale, v. 3, n. 1/2, p. 16-21, 2004. 